\title{
Acquired Brown's syndrome: an unusual cause
}

\author{
S BOOTH-MASON, , $\mathrm{G}$ M KYLE, ${ }^{23}$ M ROSSOR, ${ }^{2}$ AND P BRADBURY
}

From 'Moorfields Eye Hospital, London, The ${ }^{2}$ National Hospital for Nervous Diseases, Maida Vale, London, and ${ }^{3}$ King's College Hospital, Denmark Hill, London

SUMmARY A 62-year-old man with acquired Brown's syndrome is presented. This was due to an orbital metastatic deposit, a cause not previously reported. Other causes of this disorder and its treatment are discussed.

Inability to elevate the adducted eye above the horizontal suggests an inferior oblique weakness, but such a paresis is rare. The more common cause of this restricted movement is an abnormality of the superior oblique tendon, its sheath, or the trochlea, preventing free passage of the tendon through the trochlea during inferior oblique action. The abnormality was originally described by Brown' and is known as the superior oblique tendon sheath syndrome or Brown's syndrome.

Brown originally postulated that the cause of the motility defect was a short anterior tendon sheath on the superior oblique tendon, possibly secondary to a congenital inferior oblique weakness. However, electromyographic studies have shown that inferior oblique function is normal in the syndrome. ${ }^{2}$

In 1973 Brown $^{3}$ redefined the syndrome, describing two main groups: true, which was congenital, permanent, and due to a congenital shortening of the anterior tendon sheath of the superior oblique; and simulated, where the defect could be either permanent or intermittent, was acquired, and had various aetiologies. Brown included congenital cases in the simulated group if a cause other than a shortened anterior tendon sheath was proposed. As this aetiology is speculative, this is likely to cause confusion.

Brown's hypothesis is disputed by Parks and $M$ Brown, ${ }^{+}$who think that an abnormal tendon, lacking the normal elasticity, would better explain the clinical findings.

An abnormal insertion of the superior oblique tendon has been described" in congenital cases. The patients may not present until late childhood, and this may imply a progression of the disorder. An abnormal relationship between tendon, sheath, and

Correspondence to Miss S Booth-Mason FRCS, Moorficlds Eyc Hospital, City Road, London EC1 2PD. trochlea secondary to an abnormal insertion has been postulated as a cause of 'wear and tear' and a secondary tendon swelling. ${ }^{6}$

The mechanism of the acquired forms is either a nodule or swelling in the tendon behind the trochlea or adhesions between the sheath and tendon in its anterior parts. This would not interfere with movement of the tendon through the trochlea when the muscle is actively contracting but would prevent movement in the opposite direction.

The aertiology of the acquired form falls into two main categories: inflammatory and traumatic. The inflammatory cases can be due to local inflammation in the orbit-for example, contiguous infection of sinus or globe $^{47}$ - or part of more generalised inflammatory diseases such as rheumatoid arthritis and a tenosynovitis (as occurs in trigger-finger). ${ }^{9}$ Direct trauma to the region of the trochlea may result in the syndrome. ${ }^{10} 11$ Two cases have been described following windscreen glass injuries. These initially presented as superior oblique weakness, but the motility disorder changed spontaneously to typical Brown's syndrome about one month after injury. ${ }^{12}$ It is also seen after superior oblique tucking. ${ }^{13} \mathrm{~A}$ similar appearance is seen after some orbital floor fractures, ${ }^{14}$ although presumably the mechanism is different.

Both types may be intermittent, when the 'click' phenomenon may be present. ${ }^{6}$ An audible or palpable 'snap' is noted by patient or examiner during attempted upgaze. This phenomenon is characterised by sudden restoration of full elevation following sustained effort $^{15}$ or pressure over the trochlea ${ }^{1617}$ In congenital cases the click phenomenon is regarded as a stage in the resolution of the condition, the mechanisms postulated being either enlargement of the trochlea with growth, or 'wearing down' of the swelling with time. ${ }^{18}$ 
We present here the case of a man with an unusual cause for a typical acquired Brown's syndrome.

\section{Case report}

A 62-year-old man was admitted to hospital in June 1983 with a four-month history of double vision. He had first noticed it while shaving and only on looking up into the mirror. For the preceding three months he had suffered bifrontal headaches. He had smoked 60 cigarettes a day until three years previously but had no other relevant past medical history. There was no history of ocular disease.

On examination the visual acuity was $6 / 5$ unaided bilaterally. The visual fields, colour vision and pupil reactions were normal. The anterior segments and fundi were normal.

There was no ocular deviation in the primary position, and binocular single vision was present. There was a downdrift of the left eye on right gaze. Elevation of the left eye was almost totally restricted in adduction and near normal in abduction (Figs. $1 \mathrm{~A}-\mathrm{I})$. When the patient looked up to the right, a cover test of the right eye produced no movement of the left, and a forced duction test was positive; both findings confirmed a mechanical restriction of the eye.

The Hess chart was characteristic (Fig. 2). Overaction of the contralateral superior rectus (i.e., yoke muscle of the inferior oblique) was seen, whereas the other muscle sequelae of a true inferior oblique weakness, such as ipsilateral superior oblique overaction or contralateral inferior rectus underaction, were not present. There was no proptosis or ptosis, but the medial end of the lid crease was indistinct, though no mass was palpable. There was no tenderness, and pressure over the region did not alter the motility defect. General medical and neurological examinations were otherwise normal. Apart from a moderately raised serum alkaline phosphatase, routine haematological, biochemical, and immunological tests were negative.

Skull and orbital $x$-rays were normal, but a chest $x$-ray showed a rounded opacity in the lingula. Needle biopsy showed this lesion to be an undifferentiated carcinoma. He was subsequently found to have a carcinoma of the prostate. Computerised tomographic scan of the left orbit showed a mass in the region of the superior oblique muscle (Figs. 3A, B). There was no bony erosion around the mass. This

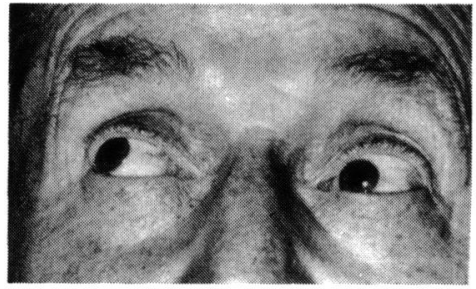

Fig. 1A



Fig. 1D

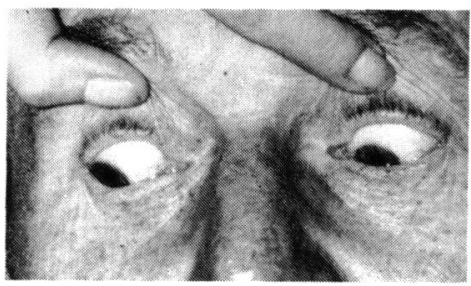

Fig. 1G

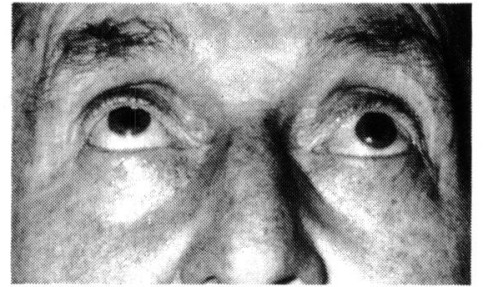

Fig. 1B

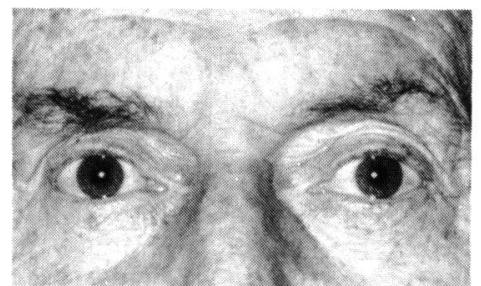

Fig. 1E

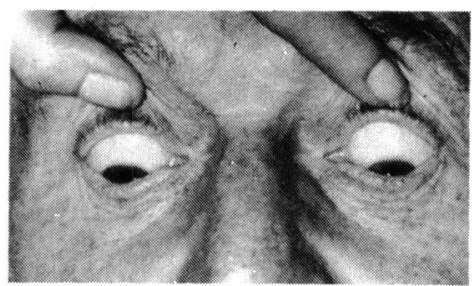

Fig. $1 \mathrm{H}$

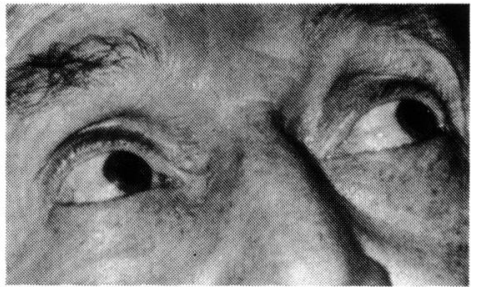

Fig. 1C

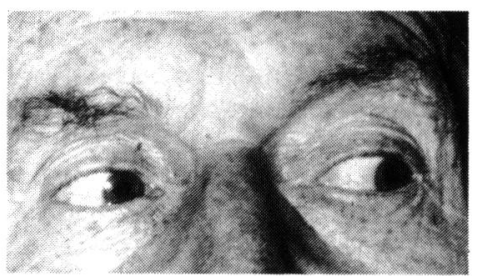

Fig. 1F



Fig. 1I

Fig. 1A-I Positions of gaze. Note restricted elevation of left eye in right gaze. 




Left Eye

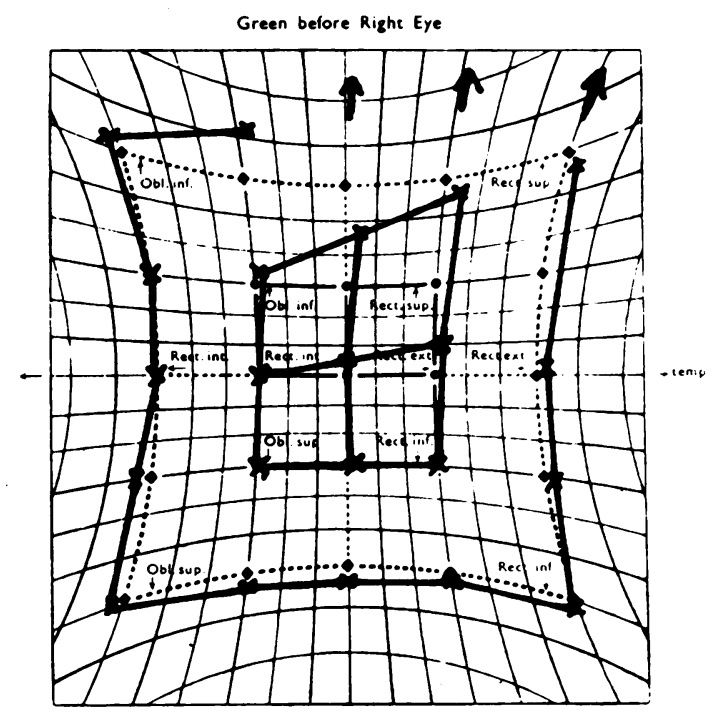

Right Eye

Fig. 2 Hess chart showing abnormality in field of action of left inferior oblique and right superior rectus only. This implies a mechanical restriction in the field of action of the left inferior oblique.

finding, together with early muscle involvement, strongly suggested a metastatic deposit.

Radiotherapy to the orbit was tried, but its effects on motility could not be accurately assessed because the patient developed cerebral metastases and deteriorated rapidly. He died shortly afterwards. Consent for necropsy was not obtained.

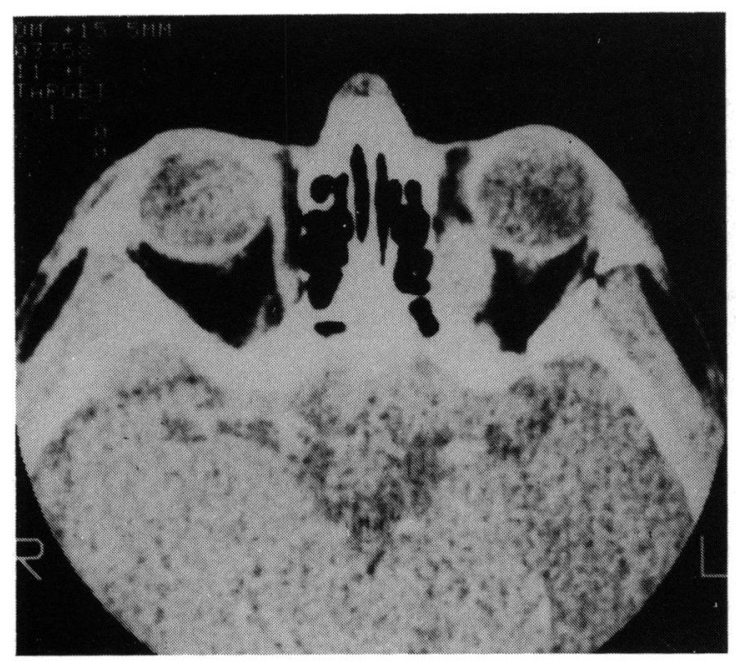

Fig. 3A

\section{Discussion}

This case fulfils all the criteria of acquired Brown's syndrome and illustrates several typical features. The lack of movement of the left eye on covering the right in dextro elevation suggests a mechanical restriction rather than a nerve palsy. This can be confirmed by

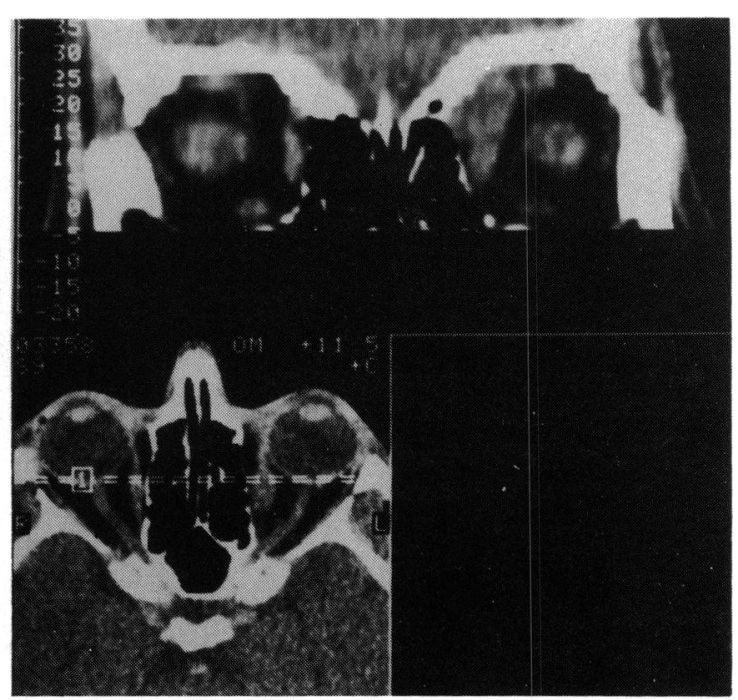

Fig. 3B

Fig. 3 (A) CT scan of orbits, with (B) coronal reconstruction, showing mass in the region of the left superior oblique muscle. 
tonometry (the intraocular pressure will increase in upgaze if the eye is mechanically restricted) and by forced duction testing. The Hess chart confirms the lack of left superior oblique overaction and right inferior rectus underaction, suggesting that the motility disorder is restricted to certain gaze positions.

The mass demonstrated by CT scan would account for the defect. It would prevent free running of the anterior tendon forwards through the trochlea during elevation, and thus restrict this duction, without interfering with superior oblique action. The normal superior oblique function suggests that inflammatory adhesion round the mass was not a significant factor in the mechanism of the restriction of movement.

If inflammatory adhesion had been thought to be a factor, peritrochlear steroid injections would have been the first line of treatment, as benefit from such management has been recorded. ${ }^{1211}$ The results of surgery in both congenital and acquired forms of the syndrome are disappointing, ${ }^{2122}$ so it was not considered because of the patient's poor general prognosis. Radiotherapy seemed logical and was tried. The deterioration in the patient's condition prevented any accurate assessment of its effects.

This case illustrates the need for a thorough systemic examination in patients who present with acquired Brown's syndrome. Associated systemic disease may be uncovered, and its nature may give a clue as to the pathophysiology of the syndrome and thus indicate which treatment may help.

We thank Professor W I Macdonald for permission to report this case under his care, Mr D Taylor for his helpful advice, Mr C Clements for help with the illustrations, and Mrs K Kyle for secretarial assistance.

\section{References}

1 Brown HW. In: Allen JH, ed. Strabismus ophthalmic symposium (1). St Louis: Mosby, 1950.
2 Catford VG, Dean Hart JC. Superior oblique tendon sheath syndrome: an electromyographical study. Br J Ophthalmol 1971; 55: $155-60$.

3 Brown, HW. True and simulated superior oblique tendon sheath syndromes. Doc Ophthalmol 1973; 34: 123-6.

4 Parks MM, Brown M. Superior oblique tendon sheath syndrome of Brown. Am J Ophthalmol 1975; 1: 82-6.

5 Babel, J, Koral S, Forrer H. Une variation anatomique du syndrome de Brown. J Fr Ophtalmol 1980; 35: 315-8.

6 Sandford-Smith JH. Intermittent superior oblique tendon sheath syndrome: a case report. Br J Ophthalmol 1969; 53: 412-7.

7 Clark EA. A case of apparent overaction of left superior oblique. Br Orthopt J 1966; 23: 116-7.

8 Wright KW, Silverstein D, Marrone AC, Smith RE. Acquired inflammatory superior oblique tendon sheath syndrome. A clinicopathologic study. Arch Ophthalmol 1982; 100: 1752-4.

9 Sandford-Smith JH. Superior oblique tendon sheath syndrome and its relationship to stenosing tenosynovitis. Br J Ophthalmol 1973; 57: 859-64.

10 Joensch PA. Paresen der achrage Heber. Graefes Arch Clin Exp Ophthalmold 1929; 121: 113-5.

11 Haas MD. Zur Pseudoparese de $M$. obliquus inferior (Taumatisches Sheath-Syndrom). Klin Monatsbl Augenheilkd 1964; 144: 118-21.

12 Trimble RB, Kelly V, Mitchell M. Acquired Brown's syndrome. In: Ravault AP, Lenk M, eds. Trans v Int Orthoptic Congress. Lyons: LIPS, 1983: 267-73.

13 Expresson Y, Hudelo J, Weiss JB. Syndrome et pseudo-syndrome de Brown. Bull Soc Ophtalmol Fr 1969; 69: 812-5.

14 Zipf RF, Trokel SL. Simulated superior oblique tendon sheath syndrome following orbital floor fracture. Am J Ophthalmol 1973; 75: 700-5.

15 Girard LJ. Psuedoparalysis of inferior oblique muscle. South Med J 1956; 49: 342-3.

16 Goldstein $\mathrm{JH}$. Intermittent superior oblique tendon sheath syndrome. Am J Ophthalmol 1969; 67: 960-2.

17 Breinin GM. New aspects of ophthalmoneurologic diagnosis. Arch Ophthalmol 1959; 58: 375-88.

18 Waddell E. Brown's syndrome revisited. Br Orthopt J 1982; 39: 17-21.

19 Herman JS. Acquired Brown's syndrome of inflammatory origin. Arch Ophthalmol 1978; 96: 1228-32.

20 Beisner DM. Acquired Brown's syndrome of inflammatory origin. Arch Ophthalmol 1979; 97: 173.

21 Mills PV, Coate MA. A case of acquired intermittent inferior oblique 'palsy'. Br Orthopt J 1967; 24: 132-7.

22 Parks MM. The superior oblique tendon. Trans Ophthalmol Soc UK 1977; 97: 288-304. 